\title{
NUMISMÁTICA Y PROPAGANDA ALMOHADE
}

SALVAdOR Fontenla BALLESTA

Madrid

\section{Generalidades}

Es evidente la relación de la numismática con la historia política, como documento emanado del poder público. Los tipos y leyendas de las monedas expresan inequívocamente la posición religiosa, política y económica del poder emisor.

Las motivaciones políticas e ideológicas del sistema monetario almorávide han sido examinadas por Kassis (1988, 55-66). La capacidad reformadora de los almohades alcanza a su numismática con nuevas formas, metrología y leyendas, con las que también transmitían sus mensajes religiosos e ideológicos. Destacan las fuentes el importante rango de los encargados de la ceca, indicio de la importancia concedida a la renovación numismática almohade para difundir sus lemas propios (Viguera, 1996, 79).

\section{FORMAS}

Las monedas almohades son fáciles de reconocer. La nueva forma característica introducida por los almohades es el cuadrado. Las de plata son de forma cuadrada y las de oro, aunque redondas, llevan en cada área un cuadrado inscrito, que divide a las leyendas en un campo central y cuatro segmentos.

La forma cuadrada en las monedas fue utilizada por los almohades como elemento de diferenciación y de propaganda. Sus jefes políticos y religiosos difundieron que la adopción del dirhem cuadrado fue profetizada por un astrólogo, y aunque bien puede ser una versión apócrifa, demuestra la importancia religiosa y política que tuvo el formato cuadrado en las monedas almohades, y así lo entendieron sus enemigos: 
- La trascendencia de esta forma fue suficiente para formar la leyenda. Así, el visir del emir almorávide 'A $\overline{1}$ b. Yūsuf designa al-Mahdī Ibn Tümart como «el señor del dirhem cuadrado» (Ibn Jaldūn, I-301, II-169).

- El emir Idrīs I, al separarse de la ortodoxia almohade, escribió a todas las provincias para que abandonasen la secta de al-Mahdi y las innovaciones que había prescrito y ordenó suprimir el nombre de al-Mahdī en la oración pública y en los dinares y dirhemes, y hacer redondos los dirhemes acuñados (Ibn Abī Zar' [1964], 487 y 488). Seguramente se corresponde con el núm. 26 de Prieto Vives (1915), que es redondo y no menciona a al-Mahdī.

El rebelde andalusí Ibn Hūd (625/1228), feroz enemigo de los almohades que hizo purificar sus mezquitas y reconoció al califa 'abbāsí, acuñó pronto monedas de oro y plata siguiendo el modelo almorávide (Torres, 1974, 83). La primera dobla redonda de tipo almorávide está fechada en el 626/1228 (Rodríguez Lorente, 1984, 99).

Las verdaderas monedas almohades de plata son cuadradas y, si bien existen algunas redondas de tipo almorávide, donde se menciona a al-Mahdi (Vives, 1893, núms. 2.014 a 2.018) y a 'Abd al-Mu’min (Abdelmumen) (Vives, 1893, núms. 2.043 a 2.045), seguramente fueron acuñadas en al-Andalus durante la rebelión antialmorávide (Prieto Vives, 1915, 31).

La forma cuadrada parece recordar los dinerales o ponderales monetarios. Los dinerales medievales tienen sus precedentes en los ponderales bizantinos, que generalmente eran de flan cuadrado (Mateu, 1934, 9, 11 a 14). La mayoría de los ponderales de dinar, desde el califato de Córdoba hasta los almorávides, tienen forma cuadrada (Ibrahim, 1993, 65).

La veracidad de los pesos está entre las obligaciones del dogma islámico, como lo demuestran los versículos coránicos 181 y 182 (azora 26), 7 al 9 (azora 55) y 1 al 3 (azora 83). Los dinares y los dirhemes debían tener su peso justo, como disponía la ley, de donde del uso continuo, lo que era por sí una cosa contable, se convertía al mismo tiempo en ponderable (Mateu, 1934, 16). La asimilación formal de la moneda almohade al dineral parece querer mostrar la aceptación plena y cumplimiento del mandato coránico como la bondad del peso de la moneda almohade, equivalente al patrón o pieza de peso justo o legal.

La continuidad de los mismos tipos de monedas almohades de oro y plata, acuñados por los nazaríes y meriníes, es consecuencia de su probado prestigio y garantía de reconocimiento y admisión en el mercado, prevaleciendo su valor ponderal sobre otras consideraciones políticas, sin olvidar que en la gran mezquita de Granada todavía se mencionaba a al-Mahdi hacia el año 740/1339 (Fierro, 1997, 451). 


\section{MetrologíA}

Los almohades introdujeron, en principio, un dinar de 2,30 g., más pequeño que el dinar almorávide de 4,2 g. Esta reducción de peso debió ser más debido a la falta de suministro de oro por la ruta sahariana que a razones ideológicas (Kassis, 1997, 322).

El emir Ya'qūb vio que el dinar era despreciado, por lo que decretó en el año 581/1185 la reforma monetaria del dinar, aumentando su peso, su valor y su precio en el doble (Ibn 'Idāāī [1983], III, 154). Establece el dinar o dobla de 4,66 2/7 g., peso aproximado al que se suponía que era el peso teórico del dinar de La Meca en tiempos del Profeta (4,55 g. del sólido bizantino), o mizcal sagrado de La Meca. Dato que obliga a reconsiderar las doblas atribuidas a 'Abd al-Mu'min.

El valor de las monedas no figura nunca en las monedas almohades. El sistema almorávide para los quirates es un antecedente (Vives, 1893, LXXXIII), aunque en la plata el nombre del imam al-Mahdi señala el dirhem, que es el dirhem cuadrado de plata que pesa 1,55 g., conocido en las fuentes como dirhem imāmī (Kassis, 1997, 331), mientras que 'Abd al-Mu’min, segundo personaje en importancia en la genealogía almohade, indica los semidirhemes, denominados dirham mu'min̄̄ (Marrākuši [1938], 163 y 196). La orla era el lugar donde se grababa el valor, por lo que, al faltar la orla, no hay espacio para el mismo, pero sobre todo porque se consideraba que no hacía falta, al ser equivalente la moneda al ponderal dineral, y por tanto la indicación de su valor innecesaria.

La dobla almohade es un antecedente y debió tener las mismas motivaciones económicas y de prestigio dinástico que tuvo la primera reforma de los Reyes Católicos, datada en 1475, en la que tomaron como unidad el «doble del castellano» o excelente, con un peso de 9,20 g. (Gil Farrés, 1976, 375). En el caso almohade se trató posiblemente de contrarrestar el intento de Alfonso VIII de dominar el mercado de oro acuñando sus «morabetinos» en Toledo (Kassis, 1997, 322), que los acuñó desde el año 1174 al 1217 (1212 a 1255 de la era de Safar), con un peso medio de 3,82 g. (Rada, 1892, 190).

\section{LEYENDAS}

La importancia relativas de las leyendas está marcada por el orden de lectura, es decir: 
1. $\quad$ Centro de la I Área.

2. $\quad$ Segmentos de la I Área.

3. Centro de la II Área.

4. ${ }^{\circ}$ Segmentos de la II Área.

La distribución de las leyendas en las doblas, moneda insignia de los almohades, es la siguiente:

La primera área contiene siempre la leyenda religiosa principal y el título y nombre del emir reinante.

La segunda área tiene al principio una leyenda religiosa, que es sustituida posteriormente por el origen genealógico del emir reinante, que demuestra su origen legítimo y ortodoxo, y en los segmentos la relación genealógica que une al emir reinante (segmentos de la I A) con su origen dinástico; es decir, dieron más valor a mostrar la legitimidad dinástica sobre la propaganda religiosa, que se redujo a lo indispensable.

\subsection{Leyendas religiosas}

El número de leyendas religiosas de esta dinastía no es muy grande.

«Y vuestro Dios es Dios único. No hay más Dios que Él, el Clemente, el Misericordioso» (s. II, 163). Se encuentra en las áreas de los dinares de 'Abd al-Mu'min y de Yūsuf I, y en las doblas de Ya'qūb en el margen de la I área; refleja fielmente la teología almohade.

"Y alabado sea Dios único», adoptado por Ya 'qūb como lema de la dinastía (Prieto Vives, 1915, 24); encabeza siempre sus escritos (Castrillo, 1997, 141), y no consta en las doblas de 'Abd al-Wāhid II y 'A

Destaca la reiteración de la unicidad de Dios, al continuar esta leyenda con la profesión de fe musulmana, concordando con la doctrina unitaria almohade del tawhìd o fórmula de la unicidad divina (Bosch, 1995, 207), pues la misión del Profeta no consistía en proclamar la presencia de Dios, sino su unicidad (Cortés, 1986, 100). La doctrina almohade sobre la unidad absoluta de Dios es puesta de manifiesto por la sahāada y por el testimonio de la incuestionable autoridad divina (Bel, 1933, 11):

— «Todo el poder es de Dios» (S. 3, 148).

— «No hay fuerza sino en Dios» (S. 18, 39).

— «No tenéis gracia que no proceda de Dios» (S. 16, 53).

— «Mi éxito sólo está en Dios» (S. XI, 88). 
Una de las cartas atribuidas a Ibn Tümart incita a aprender el credo tawhìd y la primera azora del Corán (Fierro, 1997, 444): «Alabado sea Dios Señor de los mundos» (S. 1, v. 1). «Los mundos» indica los reinos mineral, vegetal y animal; la fórmula «Señor de los mundos» es frecuente en el targum (Vernet, 1963, 26).

\subsection{Al-Mahdi}

Los almorávides reconocieron siempre la supremacía religiosa de los califas de Oriente; en cambio, Ibn Tümart al-Mahdỉ afirma la obligatoriedad de creer en el Imāmato, de obedecer al Imam, autoconectándose con el antiguo imamato del profeta Muhammad, Abū Bakr y 'Umar; por eso los fieles musulmanes deben creer en él, seguirle e imitarle, tanto en asuntos espirituales como materiales (Viguera, 1997, 79), es decir, ostentaba la doble jefatura suprema, religiosa y política.

El guía espiritual al-Mahdī significa literalmente «El que va por el buen camino», y está en todas las monedas, excepto en los dirhemes redondos a nombre de 'Abd al-Mu'min, que ya hemos dicho que, en realidad, son indicativos de valor y que, además, se acuñaron también en otros reinados, porque se emitió en ciudades que reconocieron a los almohades después de la muerte de 'Abd al-Mu'min.

El nombre de al-Mahdi puede aparecer en alguna de las siguientes formas:

— «Al-Mahdi es el Imam del pueblo.»

— «Al-Mahdi es el Califa de Dios.»

- «Al-Mahdi es nuestro Imam.»

Y por asociación de ideas emplearon también el término «dirección (hudā)», de la misma raíz que al-Mahdī: «La dirección de Dios es la dirección verdadera.»

El nombre de al-Mahdi, así como el del emir, van en la II área, en los dinares de 'Abd al-Mu’min y de Yūsuf I, y pasan al campo de la I área a partir de Ya'qūb, volviendo a la II área con 'Abd Allāh al-Bayyāsī, que se proclamó califa en 622 , y con 'Umar, a quien, dada su precaria situación en Marruecos, las escasas cecas conocidas (Ceuta, Siŷilmāsa y Málaga) sólo le reconocieron nominalmente, e Idrīs (Prieto Vives, 1915, 31). La mayor superficie de las doblas permitió dar la importancia que se merecía al nombre 
de al-Mahdi, relegado por leyendas religiosas importantes en los dinares y dirhemes, y quizá por pudor de ponerlo en el mismo lugar preferente que Dios y Muhammad, mientras que la postergación a la II área en las doblas de al-Bayyāsì, ' Umar e Idrīs II, tiene otras connotaciones socio-religiosas, posiblemente el enfriamiento de la devoción al fundador y de su doctrina.

El orden de importancia, desde el punto de vista religioso, viene definido por el reverso de los dirhemes anónimos: primero Dios (nuestro Señor), después Muhammad (nuestro Profeta) y después al-Mahđī (nuestro guía) (Bel, 1933, 10). Por su parte, 'Abd al-Mu’min representa el poder temporal, conferido por el al-Mahdi en el año 517/1123, que entonces toma el título de amīr al-mu'minīn (al-Marrākuši, 137 y 166).

Los almohades buscaron inicialmente la legitimidad religiosa, asumiendo el Califato como herederos del Profeta y posteriormente, a partir de Idrīs I, como herederos de los califas omeyas de Córdoba para atraerse el apoyo de la población andalusí (Fierro, 1997, 446 y 447).

Una de las primeras innovaciones de Idrīs I, después de su proclamación en Marrākuš, fue la pública denuncia de Ibn Tümart, eliminando su nombre de las monedas (Ibn Abī Zar` [1972], 251), pero de todo esto no queda por ahora constancia en las monedas conocidas, y ello lleva a sugerir que la única moneda cierta de este emir (Vives, 1893, núm. 2.076) fue acuñada por él como rebelde, antes de su proclamación en Marrāku (Rodríguez Lorente e Ibrahim, 1987, 59).

Muerto repentinamente Idrīs I, le sucedió su hijo 'Abd al-Wāhid II (630/1232-640/1242), quien restableció el culto a al-Mahđi en el año 631/1233 (Prieto Vives, 1915, 30). Las doblas de este emir con la invocación alQur'ān (Prieto Vives, 1915, núm. 14) son anteriores a esta fecha, y las que invocan al-Mahdī (Prieto Vives, 1915, núm. 15) posteriores. Sus monedas de plata con el título al-rašid (el ortodoxo), indican que se acuñaron cuando aún estaban vigentes las reformas de su padre Idrīs I.

La referencia al Corán podría ser con la intención de volver a las fuentes de la revelación y considerar heterodoxa la doctrina de al-Mahdi. Esa misma intención tendría 'Abd al-Wāhid II al titularse «el ortodoxo». La utilización del Corán fue también un intento de enlazar su califato con el de los omeyas (Fierro, 1997, 448).

'Imrān, gobernador de Ceuta, quien se sublevó a su vez contra Idrīs I en el año 629/1231 (Ibn Abī Zar' [1974], 253 y 275), mantiene la supresión de Mahdī en las monedas de plata que acuñó (Rodríguez Lorente e Ibrahim, 1987, 60).

Los rebeldes antialmohades andalusíes reconocieron en sus monedas al imām ‘abbāsī. 


\subsection{Leyendas genealógicas}

Incluyen títulos y nombres del emir reinante y sus antecesores hasta 'Abd al-Mu'min.

El espacio dedicado a la relación genealógica va aumentando con los sucesivos emires. Con 'Abd al-Mu'min ocupa dos segmentos y tres líneas y cuatro segmentos con Yüsuf I, en sus respectivos dinares, y hasta cinco líneas y ocho segmentos, en las doblas, a partir de 'Abd Allāh I, obligando incluso a aumentar el número de líneas por campo hasta alcanzar 10 a partir de Ya'qūb, con la excepción de las 12 de Idrīs.

Al-Gazzā̄i, maestro del fundador Ibn Tümart, estableció que para que la autoridad del soberano sea legítima debe estar avalada por dos condiciones: ostentar el poder con títulos suficientes y legítimos, por sucesión legítima o por libre elección, y ejercerlo con arreglo a las leyes establecidas; en caso contrario, los súbditos no tienen obligación de obedecerle e incluso tienen el deber de derrocarlo (Cruz, 1996, 291). De ahí la importancia de resaltar e insistir detalladamente en las leyendas numismáticas en el origen legítimo del soberano. La bondad de la ley y peso de las monedas demostraban la probidad del emir. "'Abd al-Mu’min obró con procedentes oportunos en sus promulgaciones y en sus ingresos» (Ibn al-Kardabūs [1993], 152).

'Abd al-Mu’min, en el 549/1155, veintitrés años después de ser jurado por los jeques almohades heredero de Ibn Tümart, trastoca la estructura rigurosa del poder almohade, oligarquía tribal teocrática, en una monarquía dinástica, autocrática y hereditaria en su propia descendencia, ordenando que su heredero Muḥammad fuese invocado también en la juṭtba de la oración oficial (Viguera, 1997, 82) y recogido en las acuñaciones monetarias.

Cuando el emir reinante no desciende por genealogía directa del emir antecesor, recurre a su línea más directa con 'Abd al-Mu’min, no citando al resto, aunque hayan reinado, mientras que a sus ascendientes los titula emir, aunque sea falso, o bien el menos comprometido de «nuestro señor».

Las monedas de plata son anónimas, excepto las que están a nombre de 'Abd al-Mu'min, de las que las redondas se consideran acuñadas por él, y las que son cuadradas se consideran posteriores, en las que el nombre de 'Abd al-Mu'min señala que su valor es el semidirhem, pues en los dirhemes es el Mahdi el que marca su valor (Vives, 1893, LXXXIII).

El título más importante entre los musulmanes es el de jalifa, seguido de amìr al-mu'minin (Cruz, 1996, 31). El primero fue dado por sus compañeros al sustituto de Muhammad en la presidencia de la oración, con el concepto de lugarteniente (Cruz, 1996, 30 y 31): el primer califa fue Abū Bakr. 
'Abd al-Mu'min llevaba, además del título de califa, el de amìr almu'minin y «el establecido por orden de Dios» (Prieto Vives, 1915, 24). Yūsuf I, que descendía de 'Abd al-Mu'min, llevaba la fórmula de «hijo del califa»; Ya'qūb, que descendía de 'Abd al-Mu’min y de Yūsuf I, llevaba la de «hijo de los dos califas (dual)», y Muhammad y Yūsuf II, que ya descienden de tres y cuatro califas, la de «hijo de los califas (plural)» (Prieto Vives, 1915, 28). Yūsuf II emplea la fórmula genealógica de «hijo de los califas ortodoxos», lo que impide toda confusión con Yūsuf I, que sólo desciende de un califa (Prieto Vives, 1915, 27).

Los almohades toman el título de amīr al-mu'mininn, comandante de los creyentes, que fue tomado por 'Umar b. al-Jattāa, el segundo sucesor del Profeta y luego fue característico de las dinastías omeya y 'abbāsí, y posteriormente de 'Abd al-Rahmmān III en al-Andalus. El uso de este título tuvo amplia difusión, hasta el extremo que los emires almohades eran conocidos por los cristianos como «Miramamolín».

Muerto 'Abd al-Mu'min, le sucedió su primogénito y heredero Muhammad (558/1163), que a causa de su falta de cualidades como jefe, fue derrocado por sus hermanos Abū Ya'qūb y Abū Ḥaș 'Umar, cuando llevaba sólo cuarenta y cinco días de reinado (Rodríguez Lorente e Ibrahim, 1987, 55). En los dinares que acuñó, este monarca se titula al-amìr al-aŷall (emir nobilísimo), seguramente reflejo de su situación política inestable y la falta del juramento de los jeques almohades. No hay que olvidar, por significativo, que 'Abd al-Mu'min tardó meses, desde la muerte de Ibn Tümart, para que los jeques almohades le prestaran juramento (Viguera, 1997, 81).

Yūsuf I se proclamó emir, pero las dificultades políticas internas le impedieron tomar el título de amìr al-mu'minīn, tomando, en cambio, el de alamìr al-aŷall (Prieto, 1915, 18 y 19), sin duda por la situación de inestabilidad política que ocasionó el derrocamiento de su hermano, hasta que 'Umar se retiró como pretendiente en favor de su hermano Yūsuf I (Rodríguez Lorente e Ibrahim, 1987, 55). Yūsuf I fue jurado por los jeques almohades en el año 563/1168, y sólo entonces asumió el título de amìr al-mu'mininn, ordenando inscribir en su espada «del emir de los creyentes, hijo del emir de los creyentes» (Viguera, 1997, 90), y así también consta en sus dinares.

Las dudas sobre la atribución de los dinares de Abū 'Abd Allāh Muhammad al-amìr al-aŷall a Muḥammad I o Muhammad al-Nāșir (595/1199610/1213) se disipan si comprobamos la similitud tipológica con los dinares de Yûsuf I. Por otro lado, el tesorillo de 496 dinares almohades de Huesca, conservado en el Museo Arqueológico Nacional, que contiene tres a nombre de 'Abd al-Mu'min, seis de Muhammad y el resto de Yüsuf I, sin que con- 
tenga monedas de $\mathrm{Ya}^{c} q u \bar{b}$, refuerza que pertenezcan al hijo de 'Abd alMu'min. El hecho de que las crónicas no recojan la kunya de Abū 'Abd Allāh para el primogénito de 'Abd al-Mu'min (Rodríguez Lorente e Ibrahim, 1987, 55) no es significativo, porque tenemos la evidencia de que la citada kunya es genérica en las monedas de oro y en las cartas de los sultanes nazaríes de Granada.

La tradición de no tomar el título de amīr al-mu'minīn hasta no estar consolidado en el poder fue seguida también por Abū Zakarīyā', fundador de la dinastía hạașí, que tomó el título de al-amìr al-aŷall, tomando el título de amìr al-mu’minīn su hijo Muhammad (Prieto, 1915, 48).

\subsection{La problemática de las doblas atribuidas a 'Abd al-Mu’min (Abdelmumen)}

Las doblas en cuestión son atribuidas a 'Abd al-Mu’min por Prieto Vives (1915, núm. 0) y Brethes (1939, núms. 1007-8), o al tunecino Abū Zakarìyā’ por Hazard (1952, núms. 542 y 543). Medina $(1992,405)$ se inclina por los primeros por las observaciones de Prieto Vives y la presencia de la ceca de Fez.

El dinar almohade pesa 2,27 g. (sobre 4,2 g. del almorávide), encontrándose a partir de Ya'qūb piezas de doble peso (doblas), de 4,6 $\mathrm{g}$.

Del análisis de la dobla atribuida a ‘Abd al-Mu’min (Prieto, 1915, núm. 0 ) se extraen las siguientes conclusiones:

1. Al-Mahdi está situado en el campo de la I área, lo que no ocurre en los dinares de 'Abd al-Mu'min y sí a partir de sus hijos Muhammad y Yūsuf I.

2. $\quad$ Los dinares de 'Abd al-Mu'min llevan el nombre del Mahdi en el campo de la II área, y su nombre más modestamente en el margen. Es a partir de sus hijos Muhammad y Yūsuf cuando se fija el nombre de 'Abd alMu’min como fundador de la dinastía, en el campo de la II área.

3. La dobla conocida de Fez, que descarta su atribución a Abū Zakarīyā’ Yahyà, el califa ḥafșī de Túnez, bien pudo ser acuñada por algún emir almohade posterior a Ya'qūb, a imitación de las doblas ḥafșíes, al igual que lo hicieron Muhammad I de Granada (Rodríguez Lorente, 1983, núm. 1), y los Banū Hūd de Murcia entre los años 649 y 656 H. (Rodríguez Lorente, 1984, 106). El prestigio de la dobla hafșí de un peso de 4,72 g. (Brunschvig, 1982, 69) estimularía las limitaciones en todo el Occidente musulmán. 
Es indudable que Abū Zakarīyā' acuñó imitando los dinares de 'Abd alMu’min, por dos motivos expuestos por Prieto Vives (1915, 52): la pretensión de demostrar la descendencia de 'Abd al-Mu'min, del que se consideraban herederos legítimos en el califato, y la necesidad o conveniencia de diferenciar sus monedas del califa Yạ̣yà, contemporáneo suyo.

$\mathrm{El}$ interesante tesorillo de dinares almohades de Huesca, ya citado, contiene dinares de Yūsuf I con el título am̄ir al-mu'minìn, por tanto posteriores al año 563/1168, y posiblemente extraídos de la corriente monetaria musulmana como consecuencia del desordenado repliegue de Yüsuf ante los muros de Santarem, que le costó la vida, hipótesis avalada por la abundancia relativa de dinares de Yūsuf I amīr al-mu'minīn acuñados en Sevilla $(22,22$ por 100), seguramente para financiar la campaña, y la ausencia de monedas posteriores a este emir. Precisamente, la ausencia de doblas en un tesorillo de 496 monedas de oro, fechable al final del gobierno de Yüsuf I, es un dato más para demostrar su primera emisión por Ya‘qūb.

La cita de Ibn 'Id̄āīi sobre los dinares ya'qübíes es una información positiva, no interesada y que en su tiempo sería de dominio público, y ya hemos visto que los argumentos en contra no son resolutivos.

Parece claro que 'Abd al-Mu'min acuñó dinares con un peso de 2,30 g. y que Ya'qūb acuñó con doble peso los dinares yaqubíes o doblas. La dobla atribuible a 'Abd al-Mu’min fue acuñada por un emir almohade contemporáneo del emir hạașí Abū Zakarīyā', o inmediatamente posterior. El mayor peso de las doblas hafșíes 4,72 g. (Brunschvig, 1982, 70) estimuló las imitaciones, como las de Muhammad I de Granada y Sayf al-Dawla de Murcia.

\subsection{Inscripción de la ceca}

$\mathrm{Al}$ prescindir de las leyendas marginales, que es donde se grababa la ceca, ésta tiende a desaparecer, por lo que no la llevan frecuentemente, y si lo hacen es en caracteres diminutos en uno de los ángulos inferiores o debajo de la leyenda central, como accesorio sin importancia.

La proliferación de cecas es síntoma de debilidad del poder central (Gil Farrés, 1976, 5). Los almohades tuvieron numerosos talleres emisores en el Magreb y al-Andalus lo que concuerda con el escaso apoyo del pueblo y las concesiones que tuvieron que hacer para granjearse la voluntad de los juristas (Watt, 1981, 121 y 122), y si bien cuando la ocasión lo requería podían reunir un poderoso ejército, normalmente era insuficiente para mantener a raya a los aventureros (Watt, 1981, 119). Los Banū Gāniya de Mallorca, que 
habían desembarcado en la costa africana y tomado Bujía en el 581/1185, se aliaron con tribus bereberes y se convirtieron durante los siguientes cuarenta años en el gran elemento desestabilizador del extenso imperio almohade (Ibn Jaldūn [1983], v. 12, 507).

La escasez de monedas con el nombre de la ceca grabada, su situación marginal y el tamaño reducido de la epigrafía señalan el valor secundario que tuvo para los almohades conocer por este sistema la procedencia de las monedas, es decir, el número de monedas labradas, así como su peso y ley, que contrasta con las rigurosas y detalladas normas para el funcionamiento correcto de sus cecas, lo que hace pensar en otros procedimientos de control, como marcas (círculos, puntos, etc.). Se estima que el porcentaje de dirhemes con ceca es de un 19 a 20 por 100 (Fontenla, 1984, 155), y de los dinares de oro; según el tesorillo de Huesca conservado en el MAN, el porcentaje es de 14,31 por 100.

\subsection{Inscripción de la fecha}

$\mathrm{Al}$ igual que el valor, en las monedas almohades jamás figura la fecha de acuñación. Tradicionalmente, en la numismática árabe la designación del valor, ceca y año constituyen una leyenda tipo, pero en este caso, al romperse la fórmula, como ya hemos visto, no hay espacio para la grabación de la fecha.

\subsection{Tipos de letras}

Anteriormente, el tipo de letra usado era generalmente el cúfico, pero con los almohades el carácter de la escritura es el nasjí o cursivo, con contadas excepciones en cúfico.

El imperio almohade tenía una base bereber muy importante. La lengua bereber (al-lisān al-garbī) estuvo estrechamente relacionada con el llamamiento entre las tribus, que desconocían por completo el árabe, a unirse al movimiento almohade, y por eso sólo podía recitar el sermón de la mezquita alguien que conociera el tawhìd en bereber, y las intervenciones públicas de cualquier tipo en al-Andalus debían hacerse en las dos lenguas, en bereber para los almohades y en árabe para los andalusíes (Felipe, 1997, 359). La adopción generalizada de la escritura nasjí puede interpretarse como un elemento de identificación auténticamente marroquí, frente al cúfico asociado a la numismática de los almorávides, considerados extranjeros sahá- 
ricos (Bosch, 1995, 223). El hecho que los almorávides acunaran circunstancial y tardíamente quirates con caligrafía nasjí y que existan dirhemes almohades con escritura cúfica, posiblemente de cecas tunecinas (Medina, 1992, 399), no invalida la interpretación anterior.

\subsection{Adornos}

La parte superior de los dirhemes está decorada con sarmientos de vid, adornos de tradición greco-romana y que proliferan en esta época, y son una alusión a la prosperidad y a la abundancia (Pérez Higuera, 1994, 85).

\section{CONCLUSIONES}

La moneda almohade no constituye una excepción y fue empleada para difundir su ideología y su política, y de forma involuntaria es el fiel reflejo de datos históricos y socio-políticos.

La forma cuadrada adoptada para sus monedas sirvió para identificar a sus partidarios y por tanto fue rechazada por sus adversarios. Su adopción, posiblemente, fue para asociarla, jurídicamente y de hecho, con los ponderales, conforme al mandato coránico. Esto hizo innecesario grabar epigráficamente el valor de la moneda.

Primeramente acuñaron dinares de 2,30 g., seguramente por falta de suministro de oro, doblando posteriormente con Ya'qūb su peso y valor, para competir con los morabetinos de 3,82 g. de Alfonso VIII, asimilando de esta manera su dinar al dinar que teóricamente circuló en La Meca en el tiempo del Profeta. La dobla a nombre de 'Abd al-Mu'min fue acuñada por un emir almohade a imitación de las doblas hafșíes.

Las leyendas religiosas son escasas y poco variadas, resaltando principalmente aquéllas que reflejaban la teología almohade (S. I, 1, y S. II, 163) y el lema de la dinastía adoptado por Ya`qūb (Y alabado sea Dios único).

Las leyendas genealógicas fueron de importancia primordial, para evidenciar la legitimidad dinástica del soberano, hasta el punto de aumentar las líneas en el campo de las doblas conforme la línea genealógica iba alargándose y desplazando incluso a las leyendas religiosas. La legitimidad les provenía del hecho de ser herederos religiosos del Mahdī Ibn Tümart y herederos políticos, por línea hereditaria de 'Abd al-Mu'min. El título preferido y por el que eran conocidos fue el de amir al-mu'minin, el Miramamo- 
lín de los cristianos, con el que pretendían obtener la legitimidad religiosa, como sucesores del Profeta.

Cuando los emires almohades renunciaron a la doctrina de Ibn Tümart y buscaron el apoyo de la población andalusí, mayoritariamente mālikī, volvieron a buscar la ortodoxia en el Corán, fuente de revelación, y cambiaron el nombre de al-Mahdi por el del Corán.

La caligrafía numismática es nasjí, que puede ser un elemento de identidad nacional frente a la cúfica almorávide.

\section{BIBLIOGRAFÍA}

BEL, A. (1933). «Contribution à l'étude des dirhems de l'époque almohade», Hespèris, XVI, 1-69. BosCH VILÁ, J. (1995): Los almorávides, Granada.

BRETHER, J. (1939): Contribution à l'histoire du Maroc par les recherches numismatiques, Casablanca.

BRUNSCHIVG, R. (1982): La Berberie Orientale sous les Hafsides, Paris.

CASTRILlo Márquez, R. (1997): «Las instituciones», El retroceso territorial de al-Andalus. Historia de España VIII, fundada por R. Menéndez Pidal, Ed. M. J. Viguera, Madrid.

CORTÉs, J. (1986). Edición, traducción y notas de El Corán, Barcelona.

CRUZ HeRnÁNDEZ, M. (1996): Historia del pensamiento en el mundo islámico, Madrid.

FELIPE, H. DE (1997): «Componentes de la población. Categorías sociales. La familia», El retroceso territorial de al-Andalus, Historia de España VIII, Historia de España VIII. Fundada por R. Menéndez Pidal, Ed. M. J. Viguera, Madrid.

FIERRO, M. (1997): «La religión», El retroceso territorial de al-Andalus. Historia de España VIII, Historia de España VIII. Fundada por R. Menéndez Pidal, Ed. M. J. Viguera, Madrid.

Fontenla BALLESTA, S. (1984): «Un tesorillo de dirhemes almohades de Arcila», Gaceta Numismática, ANE 74/75, Barcelona.

GIL FARRÉs, O. (1976): Historia de la moneda española, Madrid.

HAZARD, H. (1952): The numismatic history of late medieval North Africa, New York.

IBN ABī ZAR' (1964): Rawd al-Qirtās. Traducción de Huici Miranda. Valencia.

-, (1972). Rawd al-Qirțäs, Rabat.

IBN JALDŪN (1983): Kitäb al-`Ibar, Beirut.

IBN KARDABŪS (1993): Historia de al-Andalus. Estudio, traducción y notas de F. Maíllo Salgado, Madrid.

IBRAHIM, T. (1993): «Ponderales andalusíes», Numisma, 233, 39-68.

KASSIS, H. (1988): «Notas históricas sobre las monedas de los almorávides», I. Jarique de Estudios Numismáticos Hispano-Árabes, Zaragoza, 55-56.

-, (1997): «La moneda, pesos y medidas», El retroceso territorial de al-Andalus. Historia de España VIII. Fundada por R. Menéndez Pidal, Edición M. J. Viguera, Madrid.

MARRĀKUSI (AL-) (1938): Kitāb al-Mu'ŷib fi taljīs ajbār al-Magrib. 2..$^{\circ}$ Ed. Dozy.

MATEU y Llopis, F. (1934): Catálogo de los ponderales monetarios del Museo Arqueológico Nacional, Madrid.

MEDINA GÓMEZ, A. (1992): Monedas hispano-musulmanas, Toledo.

PÉrez Higuera, T. (1994): Objetos e imágenes de al-Andalus.

Prieto Vives, A. (1915): «La reforma numismática de los almohades», Miscelánea de Estudios Árabes, Madrid, 13-144

RADA Y DELGADO, J. (1892): Catálogo de monedas arábigas españolas que se conservan en el Museo Arqueológico Nacional, Madrid. 
RodríGuez LORENTE, J. J. (1983): Numismática Nasrí, Madrid.

—, (1984): Numismática de Murcia Musulmana, Madrid.

Rodríguez LoRENTE, J. J., e IBRAhIM TAWFiQ, H. (1987): Numismática de Ceuta Musulmana, Madrid.

TORRES Delgado, C. (1974): El antiguo reino nazarí de Granada (1232-1340), Granada.

VERNET, J. (1963). Traducción, introducción y notas de El Corán. Barcelona.

Viguera Molins, M. J. (1997): «Historia política», El retroceso territorial de al-Andalus.

Historia de España VIII. Fundada por R. Menéndez Pidal. Edición M. J. Viguera, Madrid.

VIVEs EsCudERO, A. (1893): Monedas de las dinastías arábigo-españoles, Madrid.

WATT, W. M. (1981): Historia de la España islámica, Madrid.

\section{RESUMEN}

Los almohades utilizaron sus monedas para difundir sus mensajes religiosos e ideológicos, no constituyendo una excepción en este aspecto. La nueva forma cuadrada, la metrología y las leyendas de la numismática almohade reflejan la situación histórica y sus posicionamientos sociales y políticos. La forma cuadrada equipara la moneda con su correspondiente dineral y fue un elemento de identificación política. Las leyendas religiosas proclaman la teología almohade de la unicidad de Dios y el lema de la dinastía. Las leyendas genealógicas tuvieron gran importancia para evidenciar la legitimidad dinástica del soberano.

\section{SUMMARY}

The Almohades used their coins to spread their religious and ideological messages, not being an exception in this respect. The new squared form, the metrology and the legends of Almohad numismatics reflect the historical situation and their social and political standing. The squared form established an equivalence of the coin with its corresponding ponderal, this constituting a statement of identity. The religious legends reflect the Almohad theology centered around the unity of God and the motto of the dynasty. The genealogical legends deal with the dynastic legitimacy of the sovereign. 


\section{SUCESIÓN DE LEYENDAS RELIGIOSAS DEL CAMPO DE LA I ÁREA}

III Ya`qūb (580-595)

IV Muḥammad (595-610)

V Yüsuf II (610-620)

VII 'Abd Allāh I (621-624)

IX Yaḥyà (624-633)

XI 'Ali (640-646)

1. ${ }^{\circ}$ En nombre de Dios, el Clemente, el Misericordioso.

2. $\quad$ Y la alabanza a Dios único.

3. ${ }^{\circ}$ Sólo hay un Dios.

4. ${ }^{\circ}$ Mahoma es el enviado de Dios.

5. El Mahdì es el Imām del pueblo.

'Abd Allāh (622-623). El rebelde de Baeza. Se sublevó y se proclamó califa en el 622.

1. $\quad$ En nombre de Dios, el Clemente, el Misericordioso.

2. ${ }^{\circ}$ Bendiga Dios a Mahoma.

3. ${ }^{\circ}$ Y a los suyos. La alabanza a Dios único.

4..$^{\circ}$ Sólo hay un Dios. Mahoma.

5. $\quad$ Es el enviado de Dios. La protección.

6. (II C): El Mahdī es el imām del pueblo.

\section{Idrīs I (624-629)}

1. ${ }^{\circ}$ En nombre de Dios el Clemente, el Misericordioso.

2. ${ }^{\circ}$ Bendiga Dios a Mahoma y a los suyos.

3. $\quad$ Y la alabanza a Dios único.

4. ${ }^{\circ}$ Sólo hay un Dios.

5. Mahoma es el enviado de Dios.

6. El Mahdì es el Imām del pueblo.

X 'Abd al-Wāhid II (630-640)

1. En nombre de Dios el Clemente, el Misericordioso.

2. $\quad$ Bendiga Dios a Mahoma y a los suyos.

3. ${ }^{\circ}$ Sólo hay un Dios.

4. ${ }^{\circ}$ Mahoma es el enviado de Dios.

5. El Corán es la prueba de Dios.

X 'Abd al-Wāhid II (630-640). Restablece el nombre de al-Mahdī en el 631.

XI 'Ali (640-646)

1. $\quad$ En nombre de Dios el Clemente, el Misericordioso.

2. ${ }^{\circ}$ Bendiga Dios a Mahoma y a los suyos.

3. ${ }^{\circ}$ Sólo hay un Dios.

4. ${ }^{\circ}$ Mahoma es el enviado de Dios.

5. El Mahdī es el Imām del pueblo. 


\section{XII ‘Umar (646-665)}

XIII Idrīs II (665-667)

(Distribución similar a la de 'Abd Allāh)

1..$^{\circ}$ En nombre de Dios el Clemente, el Misericordioso.

2. Bendiga Dios a Mahoma y a los suyos.

3. ${ }^{\circ}$ Y la alabanza a Dios único.

4. Sólo hay un Dios.

5..$^{\circ}$ Mahoma es el enviado de Dios

1. (II C). El Mahdī es el Imām del pueblo.

Cuadro 1

Espacio reservado para genealogía

\begin{tabular}{|c|c|c|c|c|}
\hline Núm. & Emir & Núm. lin/seg. & Genealogía: lin/seg. & Observaciones \\
\hline 1 & 'Abd al-Mu’min & $6 /(8)$ & $0 / 2$ & Dinar \\
\hline 2 & Yūsuf I & $8 /(8)$ & $3 /(4)$ & Dinar \\
\hline 3 & Ya'qūb & $10 /(8)$ & $3 /(4)$ & \\
\hline 4 & Muḥammad & $10 /(8)$ & $4 /(8)$ & \\
\hline 5 & Yūsuf II & $10 /(8)$ & $4 /(8)$ & \\
\hline 6 & 'Abd al-Wāḥid I & & monedas desconocidas & \\
\hline \multirow[t]{2}{*}{7} & 'Abd Allāh & $10 /(8)$ & $5 /(8)$ & \\
\hline & Al-Bayyāsī & $10 /(8)$ & $4 /(6)$ & Línea no directa \\
\hline 8 & Idris I & $12 /(8)$ & $6 /(8)$ & \\
\hline 9 & Yaḥyà & $10 /(8)$ & $5 /(8)$ & \\
\hline 10 & 'Abd al-Wāḥid II & $10 /(8)$ & $5 /(8)$ & \\
\hline 11 & $\mathrm{c}^{\mathrm{A}}$ & $10 /(8)$ & $5 /(8)$ & \\
\hline 12 & 'Umar & $10 /(8)$ & $3 /(8)$ & Línea no directa \\
\hline 13 & Idrīis II & $10 /(8)$ & $3 /(8)$ & Línea no directa \\
\hline
\end{tabular}

